\title{
Anabases
}

ANABASES Traditions et réceptions de l'Antiquité

$15 \mid 2012$

Varia

\section{Luciano CANFORA, La meravigliosa storia del falso Artemidoro}

\section{Germaine Aujac}

\section{(2) OpenEdition}

\section{Journals}

Édition électronique

URL : http://journals.openedition.org/anabases/3813

DOI : 10.4000/anabases.3813

ISSN : 2256-9421

\section{Éditeur}

E.R.A.S.M.E.

\section{Édition imprimée}

Date de publication : 1 avril 2012

Pagination : 250-252

ISSN : 1774-4296

\section{Référence électronique}

Germaine Aujac, «Luciano canfora, La meravigliosa storia del falso Artemidoro », Anabases [En ligne], 15 | 2012, mis en ligne le 01 avril 2012, consulté le 21 septembre 2020. URL : http://

journals.openedition.org/anabases/3813 ; DOI : https://doi.org/10.4000/anabases.3813

Ce document a été généré automatiquement le 21 septembre 2020.

(c) Anabases 


\title{
Luciano CANFORA, La meravigliosa storia del falso Artemidoro
}

\author{
Germaine Aujac
}

\section{RÉFÉRENCE}

Luciano CANFORA, La meravigliosa storia del falso Artemidoro, La memoria 855, Palerme, Sellerio, 2011, $254 \mathrm{p}$.

14 euros / ISBN 978-88-389-2561-0.

1 Le préambule (p.9) indique clairement la position de Luciano Canfora à propos du papyrus acquis fin juillet 2004 par la Fondazione per l'Arte della Compagnia di San Paolo et présenté comme le livre II de la Géographie d'Artémidore d'Éphèse : «Ce papyrus est l'œuvre d'un habile faussaire. " L'ouvrage de L. C. s'inscrit dans la vive polémique suscitée par l'exposition à Turin puis à Berlin dudit papyrus.

2 L. C. fut le premier à contester l'attribution de ce document au géographe grec du $\mathrm{I}^{\mathrm{er}}$ siècle avant notre ère, connu surtout par la tradition indirecte. Et il suggérait comme auteur de ce faux le grec Constantin Simonidis (c. 1820-1890), bien connu par ailleurs comme trafiquant de manuscrits, faux ou volés. C'est donc l'histoire de cette mystification qu'il se propose d'exposer dans ce livre, avec l'énergie et la force de conviction dont il sait si bien faire preuve.

3 La première partie, «Il falso del secolo » (p. 11-74), présente les éléments du problème : traduction des textes qui figurent dans les colonnes I-II et IV-V, rappel critique des Tre vite del Papiro di Artemidoro (Milan, 2006) qui accompagnait la première exposition à Turin, étrange parcours du conglomérat contenant le dit document, trouvé dans une nécropole d'Égypte, vendu à l'Arménien Serop Simonian, qui le revend à la Compagnia de San Paolo, etc. Les discussions sur tous ces points sont si serrées que je préfère laisser au lecteur le soin de les découvrir. 
4 La seconde partie, «Il moderno artefice» (p. 75-127), n'est pas moins suggestive. Voyant dans ce papyrus un faux du xix siècle, L. C. cherche dans le milieu culturel de l'époque les indices qui peuvent corroborer sa thèse, et ils sont nombreux et pertinents. C'est ainsi que le Viennois Christoph Kuffner (1780-1846) avait imaginé les voyages qu'aurait pu faire Artémidore, confondant le géographe du $\mathrm{I}^{\mathrm{er}}$ siècle avant notre ère, qu'il place à tort sous le règne de Tibère, et le philosophe expulsé par Domitien, empereur de 81 à 96 . Kuffner publia à partir de 1822 les six volumes de son Artemidor im Reiche der Römer, mais les livres v et vi parurent sous le seul titre de Artemidor. Un chapitre entier y était consacré à la fabrication des papyrus. Le lien entre géographie et philosophie, très apparent dans les colonnes I et II du papyrus de Turin, a pu être inspiré par l'ouvrage de Kuffner. Autre source d'inspiration possible, pour le Grec Simonidis, la Géographie ancienne et nouvelle, en koinè, de Mélétios d'Arta, parue à Venise en 1728, qui citait abondamment une Histoire romaine (en 37 livres) de Nicéphore Grégoras (1295-1359), laquelle retraçait seulement l'histoire byzantine à partir de 1204. De même, l'Allemand Carl Ritter (1779-1859), disciple de Humboldt (1769-1859), avait publié à Berlin en 1817 une Erdkunde, traduite en français et publiée à Paris en 1835 sous le titre de Géographie générale comparée. Et l'on peut également citer les Elementi di geografia de Nicéphore Théotokis, parus à Vienne en 1804. L'effervescence était donc grande dans les milieux proches de la géographie, mais aussi de la philosophie.

5 L. C. souligne les ressemblances du texte trouvé dans le papyrus de Turin avec l'un ou l'autre passage de tel ou tel livre cité. Autant de raisons de penser à un auteur du XIX siècle, porté sur la géographie antique et sur l'histoire byzantine. D'où le « profil de l'auteur » que dresse L. C., en s'aidant du témoignage d'un contemporain de Simonidis, Andreas D. Mordtmann (1811-1877), qui retrace la vie de ce Grec originaire de Simi, dans le Dodécanèse, mais grand voyageur, très habile à imiter les écritures et aussi compétent en chimie qu'en mécanique (p. 106-113). La cause semble donc entendue.

6 Une trentaine de planches (p.129-162) montre les documents qui ont pu servir à l'auteur des dessins que l'on trouve au verso du papyrus ou à diverses places disponibles.

7 La troisième partie, «Spiegazione dell'enigma » (p. 163-218), analyse d'abord les cinq colonnes du papyrus, dont la IV contient le seul document authentique, reproduisant le fr. 21 de Stiehle, qui remonte en définitive au De administrando Imperio de Constantin Porphyrogénète. Puis elle s'intéresse aux dessins qui comblent les vides du texte, et que L. C. rapproche du manuel de peinture byzantine de Dionigi di Furna, moine du mont Athos, que Simonidis a pu connaître lors de ses séjours dans ce monastère. L'examen approfondi des figures animales suggère qu'elles sont étrangères au texte littéraire et sûrement modernes; le verso où elles se trouvent serait donc fort suspect. D'où l'hypothèse de trois rouleaux différents, réunis pour donner l'illusion d'un ensemble prestigieux. L. C. multiplie les démonstrations en faveur de cette thèse, montrant que l'organisateur de cette supercherie ne saurait être que Constantin Simonidis. Une biographie complète de cet illustre faussaire serait certainement la bienvenue.

En appendice (p. 219-236) sont présentés divers articles de journaux, surtout italiens (La Stampa, La Republica, le Corriere della sera), relatant les divers épisodes de cette controverse autour du papyrus de Turin. Une bibliographie sélective et explicative (p. 237-241) réunit les principales publications qui sont autant de pièces à verser au procès : Luciano Canfora y tient une grande place, entraînant l'adhésion à sa thèse de maints érudits, philologues, papyrologues ou techniciens de l'écriture. 


\section{AUTEURS}

GERMAINE AUJAC

Université de Toulouse (UTM)

aujac.germaine@wanadoo.fr 